Faculdade de Ciências Econômicas UFRGS

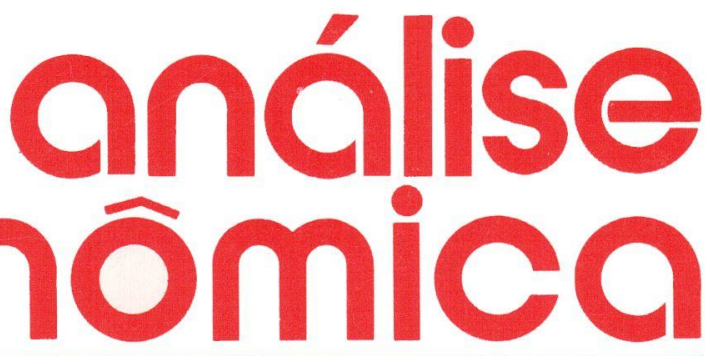

- MONETARY OVERHANG AND REFORMS IN THE 1940

Radḱger Dornbusch

Holger Wolf

- ALTA INFLAČ̃o E ESTABLLIZAÇÃo: GRADUALISMO OU TRATAMENTO DE CHOQUE

Fernando J. Cardim de Carvalho

- A ABORDA GEM MICROECONOMICA DA INDEXACAO SALARIAL

Gícomo Belbinotto Nete

- "OS NEO-RICARDIANOS" DE FRANK HAHN

Roberto Camps Mormes

- OS NEO-RICARDIANOS

Frank Hahn

- INCDENCIA TRIBUTÁRIA E OS GASTOS EM ALIMENTOS

Joso Rogerio Samson

- CONSID praÇÓES SOBRE A REFORMA TRIBUTARIA

Raymundo Guimarîtes

- eFErTgs espaciais da aUtomaÇáo BANCARIA

Moema Castro Debiagl

Otilin Beatris Kroefi Carrion

- DESENYOLVIMINTO ECONOMICO E A QUESTAO AME IENTAL

Ademar Ribelro Romeliro

- CONSIDERACóES SOBRE A DISGERTAÇAO DE MESTI ADO Nali de Jesus de Sorra
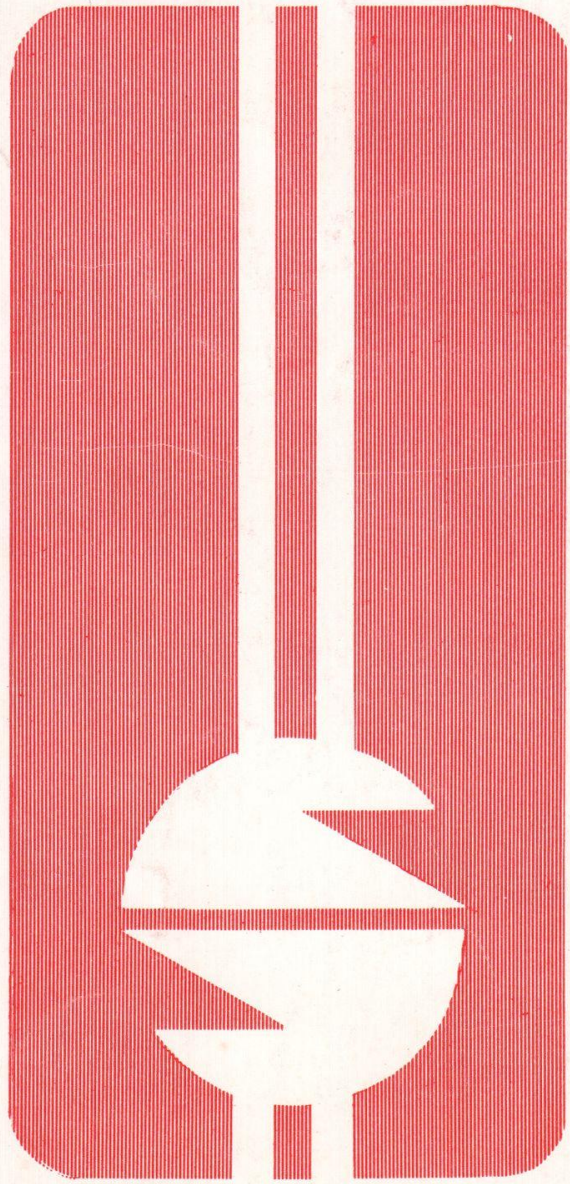
UNIVERSIDADE FEDERAL DO RIO GRANDE DO SUL

Reitor: Prof Tuiskon Dick

FACULDADE DE CIÊNCIAS ECONÔMICAS

Diretora: Prof ${ }^{a}$ Yeda Rorato Crusius

CENTRO DE ESTUDOS E PESQUISAS ECONÔMICAS

Diretor: Reinaldo Ignacio Adams

DEPARTAMENTO DE CIÉNCIAS ECONÔMICAS

Chefe: Prof. Pedro Cezar Dutra Fonseca

CURSO DE PÓS-GRADUAÇÃO EM ECONÔMIA

Coordenador. Prof. Nali de Jesus de Souza

CURSO DE PÓS-GRADUAÇÃO EM ECONOMIA RURAL

Coordenador: Prof. Atos Freitas Grawunder

CONSELHO EDITORIAL: Achyles Barcelos da Costa, Aray Miguel Feldens, Atos Freitas Grawunder, Carlos Augusto Crusius, Ernani Hickmann, João Rogério Sanson, Juvir Luiz Mattuella, Maria Imilda da Costa e Silva, Nali de Jesus de Souza, Nuno Renan Lopes de Figueiredo Pinto, Otilia Beatriz Kroeff Camion, Otto Guilherme Konzen, Paulo Alexandre Spohr, Pedro Cezar Dutra Fonseca, Reinaldo Ignacıo Adams, Roberto Camps Moraes, Valter José Stülp, Yeda Rorato Crusius, David Garlow (Wharton Econometrics Forecasts Association, E.U.A.), Edgar Auguisto Lanzer (UFSC), Eleutério F. S. Prado (USP), Fernando Holanda Barbosa (FGV/RJ), Gustavo Franco (PUC/RJ), Joaquim Pinto de Andrade (UNB), Juan H. Moldau (USP), Werner Baer (Univ. de lllinois, E.U.A.)

COMISSĀO EDITORIAL: Atos Freitas Grawunder, Pedro Cezar Dutra Fonseca, Reinaldo Ignacio Adams e Roberto Camps Moraes.

EDITOR: Nali de Jesus de Souza

SECRETARIA: Maria Ivone de Mello (normalização), Vanete Ricacheski (revisão de textos), Zélide Bregalda (Secretária)

FUNDADOR: Prof. Antôniı Carlos Santos Rosa

Os materiais publicados na revista Análise Econômica são de exclusiva responsabilidade dos autores. É permitida a reprodução total ou parcial dos trabalhos, desde que seja citada a fonte.

Aceita-se permuta com revista congêneres. Aceitam-se, também, livros para divulgaçäo, elaboração de resenhas ou recensōes.

Toda correspondência, material para publicação (vide normas na $3^{\text {a }}$ capa), assinaturas e permutas devem ser dirigidos ao seguinte destinatário:

\section{PROF. NALI DE JESUS DE SOUZA \\ Revista Análise Econômica \\ Av. João Pessoa, 52 \\ 90.040 - PORTO ALEGRE (RS), BRASIL}

Telefones: (0512) 28.1633; 24.6022 - Ramais 3440 e 3507

FAX: (0512) 25.1067 


\title{
INCIDÊNCIA TRIBUTÁRIA E OS GASTOS EM ALIMENTOS
}

\author{
Joāo Rogério Sanson*
}

\section{SINOPSE}

Discute-se a isençh̆o tributária de gastos em alimentos das classes de renda mais baixas, do ponto de vista desses possíveis beneficiários. Começa-se com a base teórica da discussto, que É a teoria da incidência de impostos. Em seguida, são apresentados resultados empíricos sobre alguns impostos indiretos. Dados sobre a incidência do ICM e do IPI mostram-nos regressivos. Dados sobre a participaçăo dos gastos em alimentos mostram-na próxima de $60 \%$ da despesa total das famflias mais pobres. E os resultados de uma simulaçá da isençio de gastos em produtos agrícolas pelo ICM são favoráveis a essas famńlias.

\section{INTRODUÇĀO}

Um tipo de polf́tica econômica freqüentemente discutido é o da isenção dos tributos a bens básicos nos orçamentos das famflias de baixa renda. Nesta situação, uma pergunta de natureza técnica é se tal redução de impostos pode efetivamente reduzir os preços destes produtos. Além disso, pode-se perguntar qual é a incidência dos principais tributos em tais faixas de renda quando efetivamente ocorra a redução de preços.

Os setores que aparecem nestas discussóes são geralmente aqueles mais importantes no orçamento das famflias de baixa renda: agropecuária e agroindústria. Os impostos são os indiretos, ou seja, aqueles que afetam as pessoas através dos preços das coisas que elas compram, em contraste com os impostos diretos, que afetam a própria renda das pessoas.

Nas discussões prévias à reforma constitucional de 1988, mencionou-se a possibilidade de os estados isentarem os bens de consumo essenciais do ICM. Nesse contexto, Ueda \& Torres (1984) calcularam os custos em termos de perdas de arrecadação para cada um dos estados brasileiros. Longo (1986, p.71-72) lembra que a Constituição de 1967

* Professor do CPGE-UFRGS. Este trabalho é uma versão revista de parte de um relatớrio de pesquisa sobre o mesmo assunto, financiado pela FIERGS em 1986.

ANÁLISE ECONÔMICA

ANO 9

№ 16

SETEMBRO, 1991

P.107-123 
previa que os estados isentariam os gêneros de primeira necessidade do ICM. Contudo, a versäo final dessa Constituição, de 1969, não manteve esse dispositivo. Uma discussão sobre a perda de arrecadação também é feita por Longo.

O presente trabalho pode ser considerado como um complemento daqueles, ao discutir o ponto de vista dos beneficiários de uma possível isenção tributária aos gêneros de primeira necessidade. Na próxima seção, trataremos destas questôes em nível teórico. Em seguida, apresentaremos dados sobre a incidência dos impostos indiretos e os resultados de dois estudos sobre incidência que são úteis para a presente discussão.

\section{INCIDÊNCIA TRIBUTÁRIA}

No debate sobre isenção de tributos com fins sociais, há vários tipos de argumentos. Uma forma de argumentar é que a retirada do imposto levará a uma redução imediata do preço de venda do bem em consideração, porque o imposto, embora seja recolhido pela firma vendedora, está embutido no preço de venda do bem. Outras vezes, porém, argumenta-se que o benefício apenas irá aumentar a rentabilidade das firmas. Nesse caso, o argumento pode ser tanto a favor da isenção, por tornar viável cercas indústrias, embora sem beneff́cios na forma de preços mais baixos, como contra, justamente por não haver alteração de preços de venda. Nas duas linhas de argumentação, há suposições mutuamente exclusivas. Numa iinha, presume-se que o imposto incida sobre o consumidor, enquanto que, na outra, sobre o produtor.

Essa ambigüidade surge facilmente quando se lembra que o preço de qualquer mercadoria taxada tom uma interpretação dupla. Há, por um lado, o preço líquido do imposto, que é o preço relevante para o produtor. É esse o preço considerado nas decisões de produção. Há, por outro lado, o preço uruto, aquele pago pelo consumidor. É o preço relevante para as decisões de consumo. Entre os dois está o imposto, normalmente calculado numa forma percentual. Portanto, o preço bruto da mercadoria será forçosamente igual ao preço líquido do improsto mais o próprio imposto.

Essa igualdade é, de fato, a seguinte identidade contábil:

$$
p_{B}=P_{L}+t
$$

onde $p_{B}$ E o preço bruto, $P_{L}$ é o preço líquido e $r$ é o imposto por unidade do bem. O imposto $t$ pode ser calculado sobre qualquer um dos dois preços. Por exemplo, o Imposto sobre Circulação de Mercadorias e sobre Serviços (ICMS) é calculado como uma porcentagem sobre o preço bruto, enquanto que o Imposto sobre Produtos Industrializados (IPI) e calculado sobre o preço líquido. 
Ora, essa identidade contábil pode levar a um paradoxo. Pelo lado do consumidor, parecerá que ele sempre pagará o imposto, pois este é somado ao valor efetivamente recebido pelo produtor. De outro lado, o produtor pode sempre achar que o imposto está reduzindo o preço líquido exatamente pelo valor do imposto. A resolução deste paradoxo está em perguntarmos o que ocorre ao preço de mercado existente antes da introdução do imposto.

Por exemplo, se o preço líquido igualar-se ao preço vigente antes do imposto, então o imposto incide sobre os consumidores. Isto e ilustrado pela Figura 1. Antes do imposto, o preço de mercado era $p^{*}$ e a quantidade vendida, $q^{*}$, ambos determinados pelo cruzamento da curva de demanda $D$ com a curva de oferta $S$. Após a introdução do imposto, ocorre um deslocamento para baixo da curva de demanda, do ponto de vista dos produtores, passando para $D^{\prime}$. Este deslocamento ocorre porque, do preço pago pelos consumidores, há que se abater a parte da receita unitária que vai para o governo. Para os produtores, o preço relevante $e$ o preço líquido do imposto. Assim, o preço pago pelos consumidores passa para $p_{B}$, enquanto que o preço reccivido pelos produtores, $p_{L}$, continua igual a $p^{*}$. A quantidade vendida diminui para $q t$.

Este é o tipo de suposição quanto às curvas de oferta e demanda, ao se defender isenções de tributos, com a expectativa de que o preço de venda do produto caia para o consumidor. Como a Figura 1 mostra, a redução ou retirada do imposto não só reduz o preço ao consumidor, como leva à absorção de uma maior quantidade do bem pelo mercado, pois a quantidade será maior do que $q_{t}$. Quase certamente, um maior número de pessoas passará a consumir o bem.

Um outro exemplo pode ser dado em que o preço bruto, pago pelo consumidor, permanece igual ao preço de mercado anterior à introdução do imposto. Pode-se dizer, dar, que o imposto incide sobre os produtores. Isto é ilustracio pela Figura 2. Ago,a, a quantidade de equilibrio de mercado permanece a mesma. Porém, com o imnosto, a curva de demanda relevante para os produtores desloca-se para baixo, passando de $D$ para $D^{\prime}$. O preço pago pelos consumidores, $p_{B}$, permanece igual ao preço de antes do imposto $p^{*}$. No entanto, o preço recebido pelos produtores é reduzido para $p_{L}$, exatamente pelo imposto unitário.

Este é o exemplo que se tem em mente quando se argumenta que a redução do imposto apenas irá aumentar a remuneração dos produtores, sem benefícios para os consumidores. Com a redução do imposto, ocorreria um aumento em $p_{L}, \operatorname{com} p_{B}$ ficando no mesmo nivel. É claro que se o objetivo da isenção fosse apenas uma maior remuneração para os produtores, para viabilizá-los no mercado, então este exemplo serviria para a defesa. 


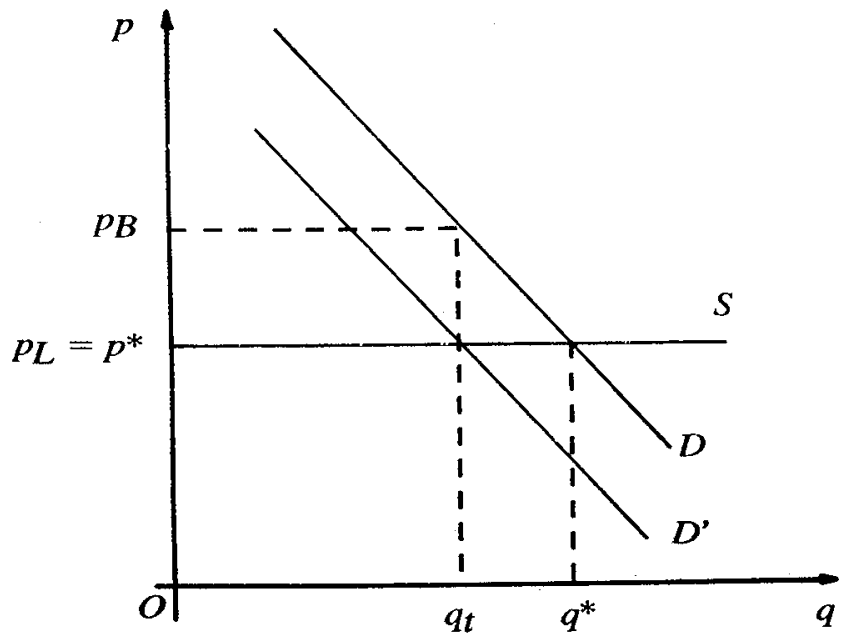

FIGURA I

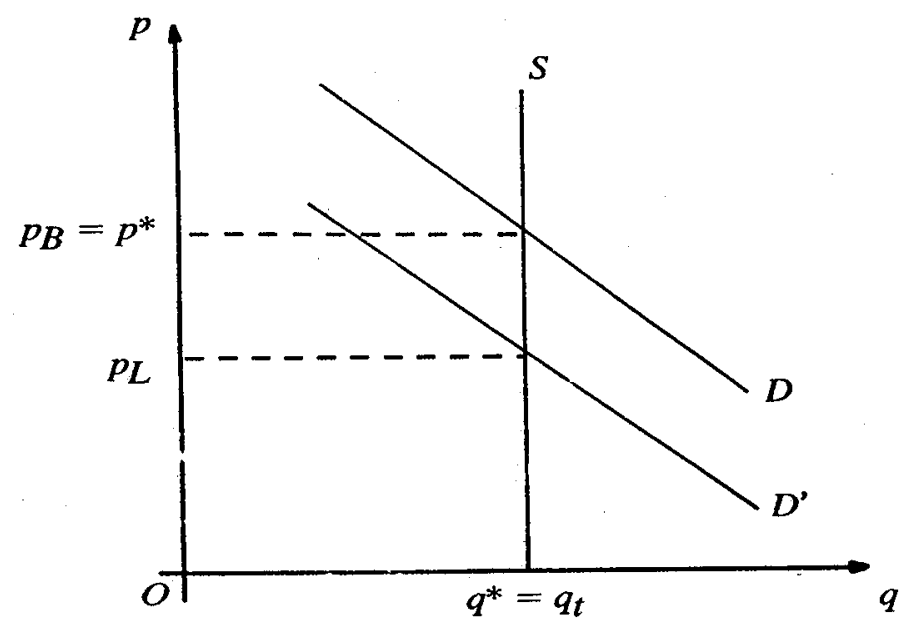

FIGURA 2 


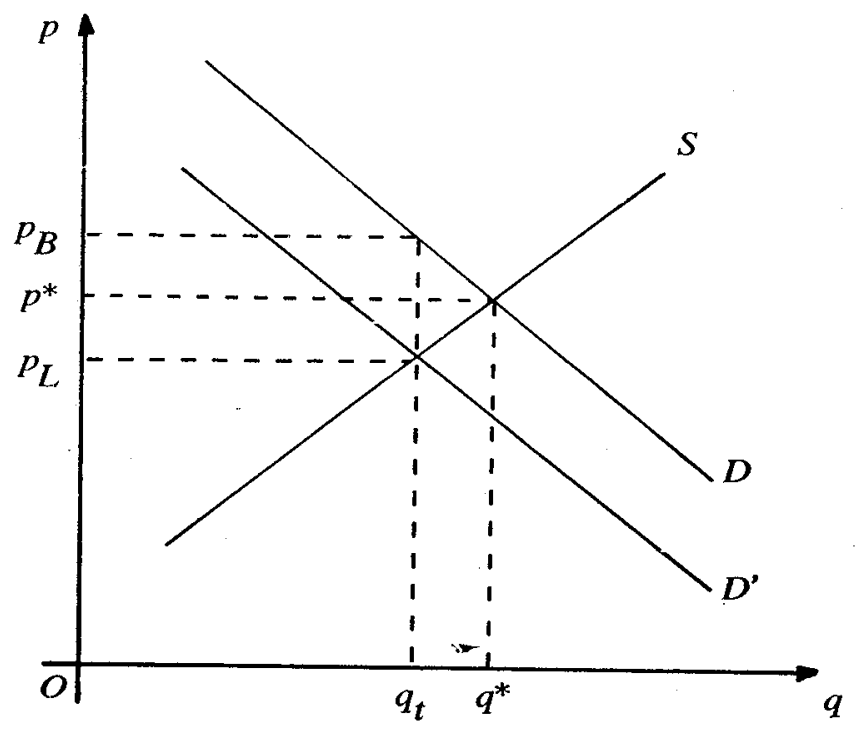

FIGURA 3

Contudo, ambos os exemplos sofrem limitaçōes por serem casos especiais. Seria preciso perguntar-se qual exemplo seria aplicável ao mercado sob discussão. Além disso, há uma infinidade de outros exemplos possfveis. Um caso mais geral, ainda para os mercados concorrenciais dos dois exemplos acima, $\epsilon$ aquele em que os preços relevantes, tanto para o consumidor como para o produtor, são ambos alterados em relação ac preço anteriơr ao imposto, mantida a identidade contábil básica. Nesse caso, o imposto incide sobre os dois lados das transações. A Figura 3 ilustra isso. Ali, $p_{B}$ e maior do que $p^{*}$, e $p_{L}$ é menor. 1

Portanto, para se falar em incidência de $n$ m imposto é preciso ter uma idéia do que ocorre com os preços das mercadorias após a introdução de um imposto. E essas alterações dependem do modelo usado para analisá-las.

Um aspecto dos modelos é o horizonte de tempo implícito na análise. Por exemplo, num primeiro momento, os produtores podem simples-

1 Discussóes mais detalhadas sobre incidência podem ser encontradas em Musgrave \& Musgrave (1980, Cap.20) e Longo (1984, Cap.13). A transferência total para a frente do imposto, como ilustrado pela Figura 1, também ocorre se a curva de demanda for uma reta vertical. Seria um caso em que os consumidores comprariam sempre a mesma quantidade, qualquer que fosse o preço. Parece ter pouca relevância empirica. 
mente alterar os seus preços pelo valor de um novo imposto. Porém, na medida em que se efetivem os ajustamentos de mercado, eles descobrirão que os seus preços podem não se manter devido à concorrência. No longo prazo, ocorrem anda os ajustamentos de entrada e sarda de firmas no mercado. É só assim, num período de tempo mais longo, que todos os ajustamentos serão completados num mercado concorrencial.

Outro aspecto crucial é o grau de concorrência num mercado, podendo os efeitos acima serem um pouco diferentes de acordo com a sua estrutura. De modo geral, porém, a incidência ocorre sobre os dois lados, mesmo que, em casos especiais, possa ocorrer um aumento de preços superior ao valor imposto. 2

Por fím, há um aspecto que diz respeito ao lado dos consumidores. $O$ fato relevante, quando se fala em incidência, é o que acontece ao "poder de compra" do consumidor, considerando que os preços de compra podem subir por causa do imposto. Com uma mesma renda monetária, um aumento de preços brutos leva a menores quantidades dos bens usualmente comprados. Numa medição de mudanças de renda real, busca-se ver o que acontece com as quantidades em média, pois as alterações de preços relativos podem levar a aumentos de quantidades para alguns bens e diminuição para outros.

Se lembrarmos que os produtores tambêm são consumidores, o mesmo racioćnio pode ser feito para eles. Do lado da produção, a incidência afeta os donos de fatores, pela diminuição da sua própria renda monetária. A redução do preço líquido tem implícita uma redução de remuneração de algum insumo. Entre os insumos podem estar o capital, matérias-primas e a mão-de-obra.

Além do imposto, é preciso levar em consideração a forma como o mesmo e gasto pelo governo. Boa parte dos impostos é gasta em bens e serviços recebidos sem pagamentos diretos pela coletividade. Os exemplos mais ‘bvios são a construção e a manutenção das vias públicas, os serviços de justiça e policiamento, a educaçāo gratuita, saúde pública, etc. Direta ou indiretamente os contribuintes são beneficiados por tais gastos, sendo que o benefício indireto ocorre quando os benefícios do serviço público acabaun incorporados aos produtos gerados pelas empresas privadas.

Em resumo, a argumentação sobre isenções tributárias pode ser feita, num primeiro momento, levando em consideração tal discussão teórica. Assim, é preciso ter uma idéia do grau de competitividade, das formas gerais das curvas de demanda e das condiçōes de custo no mercado sob consideração. Presumindo-se, por exemplo, que os mercados sejam razoaveìnente competitivos, então a redução tributária deve levar

2 Ver Musgrave (1973, Cap.13). 
a alguma redução de preços aos consumidores. Contudo, se a isenção tributária reduzir programas de gastos sociais pode-se ter o resultado acima anulado em termos da renda real destes consumidores. A possibilidade mais pessimista é que as condições de oferta e demanda sejam tais que a redução tributária apenas melhore a remuneração dos insumos sem alterar o preço ao consumidor. Isso, combinado com a redução de algum gasto que favoreça as classes de renda mais baixas, causaria uma transferência de renda normalmente inaceitável do ponto de vista social.

\section{INCIDÊNCIA DO ICM E DO IPI}

Dentro de nossa tentativa de verificar a incidência de impostos sobre a cesta básica dos consumidores de baixa renda, veremos alguns resultados já disponíveis em outros estudos. Um deles é Eris (1983), onde se estima a incidência de todo o sistema tributário brasileiro. Vejamos a seguir as estimativas desse estudo referentes ao Imposio sobre Circulaçāo de Mercadorias (ICM) e ao Imposto sobre Produtos Industrializados (IPI). Estes são os principais impostos indiretos brasileiros.

A metodologia de Eris (1983) começa pela estimativa dos preços que existiriam na ausência dos impostos. Assim, no caso do ICM e do IPI, ele obtém inicialmente os novos preçcs. Para tal estimativa é essencial saber em que grau tais preços seriam alterados como conseqüéncia das condições de oferta e demanda nos mercados competitivos. Nos mercados não competitivos é igualmente necessário ter idéia de como os preços bruto e líquido se alterariam em comparação com o preço que existiria na ausência do imposto, embora não se tenha curvas de oferta. Dadas as dificuldades de se obter informações detalhadas sobre cada mercado, os estudos de incidência tributária fazem suposições plausíveis empiricamente sobre o grau de transferência dos impostos. Transferência, nesse caso, significa alterações dos preços bruto e líquido em relação ao preço que vigiria na ausência do imposto. Uma vez tendo os preços sem imposto, recalcula-se a renda real de cada classe de renda. É um simples processo de deflacionamento da renda nominal inicial pela variação de preços. No caso, como o ponto de vista $\mathfrak{E}$ o dos consumidores, haveria um aumento da renda real se o imposto fosse eliminado.

Contudo, qual deveria ser o grau de transferência no caso do ICM e do IPI? Sabemos, pela discussão anterior, que isto depende das características dos mercados. No caso do estudo da USP, usou-se a suposição de que os impostos indiretos são repassados para os consumidores na forma de preços mais altos. Supóe-se que o preço líquido permanece o mesmo enquanto que o preço bruto sobe exatamente pelo valor do imposto. É o caso ilustrado pela Figura 1. Deste modo, a eliminação do 
imposto diminuiria o preço pago pelos consumidores exatamente pelo imposto unitário.

A Tabela 1 mostra as porcentagens de ganhos de renda real, por classe de renda, que ocorreriam caso estes impostos fossem eliminados. Os dados referem-se a 1975 . Tem-se assim uma estimativa da incidência dos dois impostos indiretos mais importantes no Brasil.

Observa-se imediatamente que ambos os impostos são bastante regressivos. O IPI começa com um acréscimo de renda de 5\% para a classe de renda mais baixa e vai diminuindo ate $1 \%$ para a classe mais alta. $O$ ICM começa com $18 \%$ e vai ate $3 \%$.

Para uma interpretação mais intuitiva de incidência de tributos, pode-se ajustar os números da tabela. Pode-se perguntar qual é o decréscimo de renda quando se passa de uma situação sem imposto para uma com imposto, em vez do que foi feito em Eris (1983). Nesse caso, para o primeiro intervalo de renda, haveria um decréscimo de $5,1 \%$ na renda por conta da introdução do IPI. ${ }^{3}$ Para o ICM, a primeira faixa de renda teria uma queda de $15 \%$ na renda.

A explicação para a regressividade de ambos os impostos está no fato de que taxam as mercadorias com alíquotas que não discriminam os consumidores por faixa de renda. Deste modo, se a alíquota é aplicada a um bem que é comprado tanto numa faixa de renda mais baixa como numa mais alta, haverá um imposto (ou uma alteração de preço) que é igual qualquer que seja a renda. O impacto, em termos de alteração da renda real, será maior para a famflia de mais baixa renda.

É interessante, contudo, observar pela Tabela 1 como o IPI $\varepsilon$ bem menos regressivo do que o ICM. A eliminação do IPI daria um acréscimo de $5,4 \%$ na renda real da classe de renda mais baixa contra $18,2 \%$ para a mesma classe sob o ICM. Pode ser visto que, para a classe de renda mais alta, a relação entre as duas porcentagens $\epsilon$ bem menos pronunciada, o que caracteriza uma maior regressividade do ICM.

A explicaçāo para esta diferença de regressividade está no caráter discriminatório das alíquotas do IPI de scordo com a essencialidade das mercadorias taxadas. O IPI taxa com alíquotas maiores os bens que, em geral, são mais importantes nos orçamentos das faixas de renda mais altas. Já o ICM taxa da mesma forma todas as mercadorias sobre as quais ele incide. Isto era especialmente verdadeiro em 1975. Após a Constituição de 1988 os Estados passaram a taxar as transações finais também de acordo com a essencialidade, embora a concorrência entre eles por base tributária enfraqueça o uso do ICM para esse fim.

3 Basta usar a formula $(I / L, 054)-I$ para a primeira classe de renda. No caso geral, $\left(Y_{1}-Y_{O}\right) / Y_{O}$, onde $Y_{1} \in$ a renda pós-imposto e $Y_{O}$ É a renda pre-imposto. Trata-se a renda comc fndices nesta conversão dos dados originais, de modo que $Y_{l}=100$. 


\section{ÔNUS TRIBUTÁRIO POR CLASSE DE RENDA DISPONIVEL: IPI E. ICM - 1975}

\begin{tabular}{ccc}
\hline $\begin{array}{c}\text { RENDA FAMILIAR } \\
\text { (SÁLÁRIOS MÍNIMOS) }\end{array}$ & IPI $^{\mathrm{a}}$ & ICM $^{\mathrm{a}}$ \\
\hline $0-1$ & 5,4 & 18,2 \\
$1-2$ & 5,2 & 14,6 \\
$2-5$ & 4,5 & 11,9 \\
$5-10$ & 4,5 & 10,0 \\
$10-15$ & 4,1 & 8,5 \\
$15-20$ & 3,8 & 7,7 \\
$20-30$ & 3,6 & 7,1 \\
$30-40$ & 3,1 & 6,4 \\
$40-50$ & 2,7 & 5,7 \\
$50-75$ & 2,5 & 5,3 \\
$75-100$ & 2,1 & 4,5 \\
Mais de 100 & 1,4 & 3,1 \\
\hline
\end{tabular}

FONTE: Eris (1983, p.129-130)

a É listada aqui apenas a alíquota mediana do imposto para classe de renda familiar.

Estes dados permitem concluir que a isenção total de um destes impostos traria benefícios relativamente maiores para as classes de renda mais baixas. Alem disso, vê-se que o ICM teria um efeito relativamerite maior para as famflias mais pobres. Naturahmente, abstrai-se, nessas conclusões, da viabilidade de tal isenção global.

\section{A IMPORTÂNCIA DOS GASTOS EM ALIMENTAÇÃo}

O estudo de incidência mencionado acima, Eris (1983), embora seja o mais completo já publicado sobre o Brasil, não permite verificar a importância dos itens da cesta básica na regressividade do ICM e do IPI. $\mathrm{O}$ que se entende por cesta básica é um conjunto de bens que constituem as despesas de uma famflia de baixa renda, em essência itens de alimentação. A questão que ainda fica sem resposta é o efeito, sobre a renda real das várias classes de renda, de se isentar de impostos indiretos tais 
itens de despesas familiares. Uma primeira aproximação a esta questão é verificar a participação das despesas com alimentos na renda familiar. $\mathrm{Na}$ verdade, examinaremos a seguir a participação dos produtos da Agropecuária e da Agroindústria.

Uma forma de se obter a cesta básica é através dos dados de estudos de orçamentos familiares. No presente trabalho, preferiu-se, em parte devido a maior facilidade de interpretação, os dados disponfveis na matriz de relações intersetoriais. A vantagem destes dados é ter os vários componentes das despesas familiares já classificados por grupos de produtos associados aos setores. Além disso, seus dados básicos são retirados de estudos de orçamentos familiares do IBGE.

A partir da matriz de relaçōes intersetoriais brasileira, de 1975, calculamos a participação nas despesas de consumo total para as cinco faixas de despesa disponf́veis. Foi preciso estimar os valores a preços de consumidor, ou seja, recalcular a participação dos itens de alimentação de forma a considerar a margem de comercializaçāo, as despesas de transporte, os impostos indiretos e os bens importados. $O$ fato de 0 IBGE (1987) ter a tabela de despesas a preço de consumidor incompleta - ver p.297, onde estão faltando quinze produtos - envolveu estimativas do consumo pessoal com base no coeficiente médio de despesas de transporte dos demais produtos da Agropecuária.

O resultado final está na Tabela 2. São porcentagens de gastos das famnlias nos produtos da Agropecuária e da Agroindústria, segundo cinco faixas de despesas, em salários mínimos de famulias para 1975. O estudo de orçamentos familiares é aquele feito pelo IBGE de acordo com as faixas de despesa $\mathrm{em}$ vez de renda, por se considerar a despesa uma variável mais consistente no estudo de 1974.

Chama atenção imediatamente a importância relativa dos gastos com alimentação: 63\% para os mais pot-es. Apesar de as bebidas estarem inclurdas em Agroindústria, dados mais detalhados mostram que tal tipo de despesa $\epsilon$ inferior a meio por cente para as familias mais pobres. Outros itens, também de pequena expressão, que näo são estritamente alimentos são lenha e carvão, embora ligados ao consumo alimentar, e fumo. Para as famnlias mais pobres, todos esses produtos, inclusive a bebida, representam $4,5 \%$ da despesa total. Para as famflias na faixa de mais de vinte salários mínimos, a participação é de $2,1 \%$. Todos os demais produtos sãu alimentos. Deve-se notar que a grande importância dos alimentos na despesa total ocorre para as famnlias na faixa de até dez salários mínimos.

A tabela deixa claro que a participação dos gastos em alimentação é decrescente se de $63 \%$, para a classe mais pobre, ate $18,6 \%$, para a classe mais alta. Este tipo de resultado $\epsilon$ conhecido como Lei de Engel, em homenagem a 
TABELA 2

\section{PARTICIPAÇÃO DOS SETORES DE AGROPECUÁRIA E AGROINDÚSTRIA NO CONSUMO PESSOAL, DAS \\ FAMÍLIAS - 1975}

\begin{tabular}{lccc}
\hline $\begin{array}{l}\text { Classes de Salários } \\
\text { Mínimos }\end{array}$ & Agropecuária $^{a}$ & Agroindústriab $^{b}$ & Total \\
\hline Ate 2 & 12 & 51 & 63 \\
2 a 5 & 9,5 & 43 & 52,5 \\
5 a 10 & 7,4 & 33 & 50,4 \\
10 a 20 & 5,2 & 23 & 28,2 \\
Mais de 20 & 3,6 & 15 & 18,6 \\
Todas as classes & 7,3 & 32 & 39,3 \\
\hline
\end{tabular}

FONTE: dados processados a partir de IBGE (1987).

a Os produtos 0101001 (Madeira em tora) a 0303091 (Outros produtos da pecuária) constituem a Agropecuária.

b Os produtos 2601001 (Cafe em grão) a 2802001 (Cigarros, charutos, cigarrilhas e fumo desfiado) constituem a Agroindústria.

Ernst Engel, que estudou orçamentos familiares de trabalhadores europeus na década de 1850 .

Tal regressividade na participação dos gastos alimentares pode explicar a propria regressividade dos dois grandes tributos indiretos, já estudados acima. Isto pode ser visto facilmente se se imaginar uma alfquota únicá dos dois impostos para todos os bens. Daf, a conta de imposto seguirá a mesma estrutura da despesa.

Poderfamos combinar as Tabelas 1 e 2 . Vimos que a total eliminação do ICM levaria a ganhos de renda real entre 15 e $18 \%$ para as famrlias de até dois salários mínimos de despesas. Como os gasîos alimentáres representam ao redor de $60 \%$ das despesas, poderfamos concluir que a sua isenção pelo ICM levaria a ganhos de renda real entre 9 e $11 \%$. Tal cálculo, no entanto, presume que a incidência sobre os gastos alimentares é igual à dos demais bens. É bastante provável que isto não seja verdadeiro, mas não houve como verificar dentro dos limites do presente trabalho.

O ICM envolve isençôes e o IPI taxa apenas os bens industrializados, mesmo assim com alíquota diferenciadas. Após 1988, o ICM tam- 
bém passou a taxar com alfquotas diferentes os vários bens. Há, assim, um complicador na relação entre a regressividade na participação das despesas alimentares e a regressividade dos impostos indiretos. Além disso, outros tipos de bens podem também envolver uma estrutura regressiva de despesas.

\section{SIMULANDO A ISENÇĀO TRIBUTÁRIA dOS ALIMENTOS}

$\mathrm{Na}$ ausência de um estudo espećf́ico, no Brasil, sobre a ligação entre a regressividade dos impostos indiretos e os gastos alimentares das famflias, pode-se recorrer a outras evidências. Elas podem ser mais precisas do que simpiesmente mencionar as participações das despesas com alimentos nos orçamentos familiares. Tal tipo de evidência pode ser encontrado em Sanson (1980a), que buscou medir a incidência da substituição do Imposto sobre Vendas e Consignaçōes (IVC) pelo ICM. A resposta à questão sobre o impacto redistributivo daquela substituição de impostos ilumina a natureza do próprio ICM. Como um imposto indireto que cobria as mesmas transaçóe sque o ICM, o IVC certamente também era regressivo. A questão, dar, passa a ser qual dos dois é mais regressivo. $\mathrm{Na}$ análise desta questão, o estudo simulou cs resultados de uma isenção tributária dos produtos alimentícios através do ICM. É esta simulação que nos interessa aqui. Porém é preciso antes resumir a metodologia daquele estudo. 4

A metodologia de Sanson (1980a) é baseada na estimativa de um modelo macroeconômico keynesiano simples, porém desagregado. $5 \mathrm{~A}$ função de produção é desagregada através de uma matriz de Leontief regionalizada. Como conseqüência, o nível de preços é explicitamente calculado como uma média dos preços de cada setor da economia. A função de consumo é também desagregada por classes de renda. São funções de consiumo lineares. Por fim, a, suposição de uma distribuição de renda monetária dada, aquela da situação inicial, fecha o modelo. A distribuição da renda monetária não muda, mesmo após a substituição tributária. O que se mede são as alterações da renda real de cada classe. Estima-se o modelo por ralibragem aos dados de contabilidade social do ano de 1967, Jcasião em que ocorreu a substituição. Simula-se, em seguida, a retirada do IVC e a inclusão do ICM. Pela mudança nos preços, chegase a um índice de preços de Fisher para cada classe de renda, que permite estimar a variação de renda real por conta da mudança tributária.

4 Ver também Sanson (1980b, 1980c e 1984). A presente seçăo adaptou uma parte de Sanson (1980c).

5 Ver Guilhoto \& Fonseca (1990) para uma comparaçăo dos vários tipos de modelagem macroeconômica. 
A Tabela 3 mostra claramente que todas as classes de renda ganharam com a substituição do IVC. Porém a disiribuição dos ganhos claramente favoreceu as classes de renda mais altas em ambas as regióes. Do mesmo modo, os ganhos foram maiores para os grupos do Centro-Sul em relação aos mesmos grupos de renda do Norte-Nordeste. Isto é equivalente a dizer que o ICM é mais regressivo do que o IVC.

Uma explicação para tal distribuição de ganhos pode ser buscada na natureza de cada um dos impostos envolvidos. O IVC era um imposto sobre todas as vendas mercantis, intermediárias e finais, tal como hoje $\varepsilon$ o FINSOCIAL. Assim, cada vez que uma mercadoria era vendida, pagava-se o imposto. Quanto maior o número de empresas envolvidas na produção da mercadoria, tanto maior era o valor do imposto incidente sobre ela. Em outras palavras, tanto maior era a alíquota efetiva sobre aquela mercadoria. Já o ICM é um imposto sobre o valor adicionado, com o uso do sistema de crédito para o cômputo do imposto a pagar. Isto quer dizer que a empresa aplica a alíquota sobre suas vendas totais e subtrai daquele valor o imposto já recolhido por outras empresas sobre os insumos utilizados por ela. Em conseqüência, o imposto incidente será proporcional apenas ao valor final da mercadoria, independendo do número de empresas envolvidas na sua produção. Assim, a alíquota efetiva será, em prinć́pio, igual à alíquota aplicada na venda final.

Tendo em vista a natureza des dois impostos, pode-se dizer que a substituição do IVC pelo ICM levou a uma maior regressiviçade devido à composição das despesas das diferentes classes de renda. Se, para um dado orçamento familiar, há uma grande porcentagem de gastos em produtos mais elaborados, certamente a carga de IVC é relativamente grande. A introdução do ICM, ao eliminar o viés contra os bens mais elaborados, implica um desafogo para esse orçamento.

Como um teste desta hipótese, o referido estudo fez uma nova estimativa dos seus resultados, imaginando uma isenção total do ICM num dos setores cujos produtos reconhecidamente envolvem um menor númuro de transaçōes entre fïmas até o seu consumo final. É o setor agrícola. $O$ peso desse setor no orçamento das classes de baixa renda era relativamente mais importante do que para as classes de mais alta renda.

$O$ resultado deste teste está na Tabela 4. Observa-se que os ganhos de renda real teriam beneficiado principalmente as classes de renda mais baixas, em oposição aos resultados acima. Isto teria sido possível, de acordo com o modelo utilizado, porque os preços dos produtos agrícolas cairiam em relação aos preços das outras mercadorias, beneficiando assim as classes mais baixas de renda.

O setor agropecuário já envolvia um bom número de isenções à Época da reforma tributária. Porém elas não foram suficientes para neutralizar o efeito regressivo da substituição. Obviamente, a idéia oposta 
TABELA 3

VARIAÇŌES NA RENDA REAL POR REGIÃO E POR GRUPO DE RENDA NA SUBSTITUIÇÃO DO IVC PELO ICM

\begin{tabular}{ccc}
\hline \multirow{2}{*}{ GRUPOS DE RENDA $^{\mathrm{a}}$} & \multicolumn{2}{c}{ REGIÃO } \\
\cline { 2 - 3 } & CENTRO-SUL & NORTE-NORDESTE \\
\hline 1 & 1,62 & 0,86 \\
2 & 1,69 & 1,07 \\
3 & 1,74 & 1,14 \\
4 & 1,87 & 1,37 \\
5 & 1,97 & 1,53 \\
6 & 2,15 & 1,79 \\
7 & 2,23 & 1,96 \\
8 & 2,47 & 2,35 \\
9 & 2,54 & 2,53 \\
\hline
\end{tabular}

FONTE: Sanson (1980a, p.66).

a $O$ Grupo de Renda 1 corresponde à classe mais baixa de renda dos estudos sobre orçamentos familiares da Fundação Getalio Vargas, feitos no perfodo de 1961 a 1963.

TABELA 4

VARIAÇÕES NA RENDA REAL NO CASO DA ISENÇÃO HIPOTETICA DO ICM SOBRE PRODUTOS DA AGROPECUÁRIA

(\%)

\begin{tabular}{|c|c|c|}
\hline \multirow{2}{*}{ GRUPOS DE RENDA } & \multicolumn{2}{|c|}{ REGIŌES } \\
\hline & CENTRO-SUL & NORTE-NORDESTE \\
\hline $\begin{array}{l}1 \\
2 \\
3 \\
4 \\
5 \\
6 \\
7 \\
8 \\
9\end{array}$ & $\begin{array}{l}4,15 \\
3,81 \\
3,82 \\
3,65 \\
3,59 \\
3,46 \\
3,29 \\
3,1 \\
2,84\end{array}$ & $\begin{array}{r}4,41 \\
4,08 \\
4,11 \\
3,93 \\
3,87 \\
3,74 \\
3,58 \\
3,41 \\
3,14\end{array}$ \\
\hline
\end{tabular}

FONTE: Sanson (19a0a, p.70).

Obs.: ver nota smbre Grupos de Renda na tabela anterior. 
de eliminar estas isenções e de outros itens que participam de forma importante no orçamento das classes inferiores de renda só agravaria o efeito líquido regressivo.

Seria um exercício interessante a estimativa dos novos padrões de incidência do ICM com uma isenção total do setor agroindustrial, em vez do setor agropecuário, embora os dois estejam estreitamente vinculados. Porém, é bastante provável que o efeito da regressividade do ICM mostrar-se-ia bem mais forte. Deste modo, tal como os produtos da agropecuária, os produtos da agroindústria ganham importância relativa quando se desce para as classes de renda mais baixas, como já vimos na Tabela 2 acima. Fica claro que um exercício de isenção de ICM dos produtos da agroindústria ou de outros produtos que estejam com suas proporções de gastos negativamente correlacionadas com a renda só reforçaria os resultados de Sanson (1980a), de que o ICM na verdade $\varepsilon$ mais regressivo do que o antigo IVC.

\section{CONCLUSÃ̃}

A partir da teoria econômica, viu-se que a isenção de impostos pode ter diferentes tipos de conseqüências. Nem sempre haverá o beneff́cio para o público-alvo, devido aos possíveis ajustamentos dos agentes económicos através do mercado. Contudo, dentro das suposições usuais nos estudos de incidência é provâvel que, das isenções de impostos indiretos, resultem preços menores para os consumidores. Entre essas suposições estão a de que os respectivos mercados são altamente competitivos, com curva de oferta horizontal, e de que se trata de prazo longo para todos os ajustamentos de mercado.

O ICM e o IVC, como principais impostos indiretos brasileiros, são candidatos usuais na isenição de bens da cesta básica. Dacios sobre a incidência destes impostos mostram que são bastante regressivos, especialmente o ICM. Portanto, se eles isentarem despesas das famflias de baixa renda, deverão dar ganhos significativos de renda real para elas.

Porém, quão importante são os gastos da cesta básica para tais famílias? Apresentamos os dados sobre as proporçőes de gastos em produtos da Agroindústria e da Agropecuária. Chegam a algo próximo a $60 \%$ da despesa familiar de até dois salários múnimos mensais, sendo bastante altas para as famflias de até dez salários mínimos de despesas mensais. Isto mostra que o impacto sobre a renda real das famflias de baixa renda de uma possivel isenção desses bens pode ser bastante significativo.

Para se ter uma idéia da importância da isenção do ICM sobre as rendas mais baixas, resumimos os resultados de um estudo sobre a substituição do IVC pelo ICM. Conclui-se que se o ICM isentasse apenas os 
produtos da Agricultura, então a maior regressividade do ICM em comparação com o IVC seria revertida.

A conclusão final ê de que a isenção da cesta básica teria efeito significativo sobre a renda real das famflias mais pobres. Contudo, tal conclusão precisa ser qualificada por vários elementos. Um desses elementos é a perda de receita, que afeta desigualmente os estados. Deve-se perguntar que bens públicos terão sua oferta reduzida para o financiamento do programa de isençôes. Se forem bens públicos orientados para as famúlias de baixa renda, é possível que o resultado líquido seja-lhes desfavorável. Outro elemento é o conjunto de suposições sobre transferência de impostos que está embutido na discussão. No caso dos produtos alimentícios é provável que as suposiçōes sejam as mais adequadas. Contudo, se evidências empíricas de estudos de economia industrial mostrarem outra realidade, então as conclusões acima serão bastante afetadas.

Um possível aprofundamento do estudo feito aqui seria simular a isenção dos vários componentes das despesas familiares. Em vez de se estudar a incidência por tipo de imposto, como fez Eris (1983), estudarse-ia a incidência por item de despesa.

\section{BIBLIOGRAFIA}

ERIS, I. et alii. A Distribuiçåo de Renda e o Sistema tributário no Brasil. In: ERIS, C.C.C., (org.) Finanças Páblicas. Săo Paulo: FIPE/Pioneira, 1983.

GUILHOTO, J...M. \& FONSECA, M.A.R. da. As Principais Correntes de Modelagem Económica e o Caso Brasileiro. In: ENCONTRO BRASILEIRO DE ECONOMETRIA, 12. Brasflia, dez. 1990. Anais... São Paulo: SBE, 1990. p.447-470.

IBGE. Matriz de Relaçбes Intersetoriais: Brasil 1975. Rio de Janeiro: IBGE, 1987.

LONGO, C.A. Finangas Pablicas. Săo Paulo: IPEJUSP, 1984.

MUSGRA VE, R.A. Teoria das Finanças Públicas. Săo Paulo: Atlas, 1973. 2v. pus, 1980.

\& MUSGRA VE, P.B. Finanças Pablicas Teoria e Prática. Rio de Janeiro: Cam-

SANSON, J,R. Incidence of the Substitution of a Value-Added tax for a Turnover tax: the Case of Brazil. Recife: PIMES - IFPE, 1980a. (Estudos, 4). - Consequêencias da Substituição do IVC pelo ICM Sobre a Renda Real de Consumidores Nordestinos e Sulistas. In: ENCONTRO BRASILEIRO DE ECONOMETRIA, Nova Friburgo, dez. 1980. Anais... Brasnlia: SBE, 1980b. p.561-590. IVC, ICM e Regressividade. In: ENCONTRO NACIONAL DE ECONOMIA, 8., Nova Friburgo, dez. 1980. Anais... Brasilia: ANPEC, 1980c. p.997-1004. An Alternative Model for Studying the Incidence of Indirect Taxes. Journal of Public Economics, v.25, p.245-254, 1984.

UEDA, E. \& TORRES, I. Estrutura Tributária Estadual: Potencialidades, Adequação e Refortaas. São Paulo: IPE - USP, 1984. (Relatórios de Pesquisa, 18). 


\section{ABSTRACT \\ TAX INCIDENCE AND FOOD EXPENDITURE}

The tax exemption of food expenditure for low income classes is discussed, from the viewpoint of these possible beneficiaries. The theoretical foundation of the discussion, which is the theory of tax incidence, is initially examined. Then, empirical results on a few indirect taxes are introduced. Results on the incidence of ICM and IPI taxes (both are value-added taxes) show them to be regressive. Results on the share of food expenditure show that it represents around $60 \%$ of total expenditures of the poorest families. And the results of a simulation, in which expenditures on agricultural products are exempt from the ICM tax, are favorable to those families. 